EXTENDED REPORT

\title{
Plasmacellular differentiation in extranodal marginal zone B cell lymphomas of the ocular adnexa: an analysis of the neoplastic plasma cell phenotype and its prognostic significance in 136 cases
}

\author{
S E Coupland, M Hellmich, C Auw-Haedrich, W R Lee, I Anagnostopoulos, H Stein
}

Br J Ophthalmol 2005;89:352-359. doi: 10.1136/bjo.2004.047092

\begin{abstract}
Aim: To determine (a) the expression of plasma cell related antigens in extranodal marginal zone B cell lymphomas (EMZL) of the ocular adnexa; and (b) the prognostic value of plasmacellular differentiation in these tumours.

Methods: A consecutive case series of 136 ocular adnexal EMZL obtained from three ocular pathology centres over 20 years was analysed retrospectively. An extensive immunohistochemical panel, including the plasma cell related antigens VS38c, CD38, CD138, multiple myeloma oncogene-1-protein (MUM1/ IRF4), and CREB binding protein (CBP) was performed. EMZL were defined as "plasmacellular differentiated" on the basis of morphological features, evidence of cytoplasmic immunoglobulin, negativity for BSAP/PAX5, and expression of at least one of the investigated plasma cell related antigens. Controls included normal or hyperplastic lymphatic tissues. Detailed clinical data were collected for most patients, and compared with the results of immunohistochemistry. The end points considered for statistical analysis were development of local tumour recurrence, development of systemic disease, and lymphoma related death.

Results: 57 (42\%) of the 136 ocular adnexal EMZL showed a plasmacellular differentiation; 45 of these plasmacytoid cases were primary tumours. In contrast with most admixed normal plasma cells, which displayed co-expression of MUM1/IRF4, Vs38c, CD38, CD138, and CBP, the plasmacellular differentiated EMZL tumour cells demonstrated co-expression of all five plasma cell related antigens in only six of $57(11 \%)$ plasmacellular differentiated ocular adnexal EMZL. The most commonly expressed plasma cell related antigen was MUMI/IRF4, immunoreactivity being seen in 56/57 (98\%) plasmacellular differentiated EMZL examined. Although the association of plasmacellular differentiation in primary ocular adnexal EMZL and disseminated disease was statistically significant on univariate analysis $(p=0.042)$, this was weaker on multivariate analysis.

Conclusion: Plasmacellular differentiated tumour cells in EMZL demonstrate an aberrant immune profile for plasma cell related antigens when compared with normal plasma cells. On multivariate analysis, plasmacellular differentiation in ocular adnexal EMZL was not significantly associated with local recurrence, the development of systemic disease, or with lymphoma related death.
\end{abstract}

See end of article for authors' affiliations

Correspondence to:

Dr S E Coupland, Institute of Pathology, CharitéMedical Faculty Berlin, Campus Benjamin Franklin, Germany, Hindenburgdamm 30, D-12203 Berlin, Germany; sarah.coupland@

charite.de

Accepted for publication 29 June 2004
$\mathrm{T}$ he ocular adnexal lymphomas (OAL) represent malignant lymphoid neoplasms which develop as primary or secondary tumour manifestations in the orbit, the lacrimal gland, the conjunctiva, and eyelid. The majority of OAL are B cell non-Hodgkin's lymphomas (NHL), with the most common subtype being the extranodal marginal zone $\mathrm{B}$ cell lymphoma (EMZL), ${ }^{1-7}$ according to the new World Health Organization (WHO) lymphoma classification. ${ }^{8}$

EMZL develop in a variety of locations normally possessing minimal lymphoid tissue, the most common site being the stomach. ${ }^{9}$ Regardless of location, these tumours have similar clinical, pathological, and molecular features. ${ }^{89}$ Usually, EMZL are low grade NHL with indolent clinical courses, although high grade transformations have been described, ${ }^{10}$ including in the ocular adnexa. ${ }^{4}{ }^{11}{ }^{12}$ Morphologically, EMZL are characterised by a mixture of centrocyte-like, monocytoid, and plasmacellular differentiated tumour cells with occasional blasts in the marginal zone surrounding reactive follicles. The degree of plasmacellular differentiation can be extensive, and may result in difficulties in distinguishing lymphoplasmacytic lymphoma/immunocytoma from EMZL in small biopsies. ${ }^{2} 71314$
The clinical significance of plasmacellular differentiation of tumour cells in small cell B-NHL in general is unclear. Patients with "plasmacytoid" B cell chronic lymphocytic leukaemia (B-CLL) are proposed to have a better prognosis. ${ }^{15-17}$ In this study, we determined which ocular adnexal EMZL could be defined as "plasmacellular differentiated" on the basis of morphology and of their immunophenotype (including evidence of cytoplasmic immunoglobulin (Ig) with light chain (IgL) restriction, negativity for B cell specific activator protein (BSAP, also known as PAX5), as well as expression of the plasma cell related antigens VS38c, CD38, CD138, multiple myeloma oncogene-1-protein (MUMl, also known as IRF4), and of the CREB binding protein $(\mathrm{CBP}))$. The results were compared with clinical

Abbreviations: APAAP, alkaline phosphatase anti-alkaline phosphatase; B-CLL, B cell chronic lymphocytic leukaemia; BSAP, B cell specific activator protein; $C B P, C R E B$ binding protein; CREB, cyclic $A M P$ responsive element binding protein; EMZL, extranodal marginal zone $B$ cell lymphomas; Ig, immunoglobulin; IgH, immunoglobulin heavy chain; IgL, immunoglobulin light chain; MUM1/IRF4, multiple myeloma oncogene-1-protein; NHL, non-Hodgkin's lymphomas; OAL, ocular adnexal lymphomas; $\mathrm{RLH}$, reactively hyperplastic lymphoid tissue 
data, in particular, with the development of local tumour recurrence, of systemic disease, and of lymphoma related death to establish whether plasmacellular differentiation of ocular adnexal EMZL has any value in the prediction of these events.

\section{METHODS}

\section{Tissue samples}

A series of 136 consecutive cases of ocular adnexal EMZL were collected and slides retrospectively reviewed from the pathology departments of Charité-Medical Faculty Berlin, Campus Benjamin Franklin, Berlin, Germany, and of Western Infirmary, Glasgow, UK, as well as the Department of Ophthalmology, University Hospital Freiburg, Germany. The cases, which were collected between the 1980 and 2000, were assessed on the basis of morphology and immunophenotype, and classified according to the new "World Health Organization (WHO) Classification of Tumors of Haematopoietic and Lymphoid Tissues". ${ }^{8}$ Only those cases with biopsies of sufficient size, adequate morphology, appropriate fixation (4\% buffered formaldehyde), and clinical information were analysed. In addition, 10 cases of normal or reactively hyperplastic lymphoid tissue (RLH) - for example, hyperplastic tonsil and lymphoplasmacellular infiltrates within lacrimal glands, were evaluated.

\section{Immunohistology}

Immunohistochemical investigations were performed using monoclonal and polyclonal antibodies reactive in paraffin sections. A pressure cooker antigen retrieval method was performed before immunohistochemical staining. ${ }^{18}$ The staining consisted of a first stage incubation with the following primary monoclonal antibodies against the following antigens: CD79a; CD20; BSAP/PAX5; CD5; CD10; CD21; CD23; CD43; BCL2; cyclin Dl; BCL6; VS38c; CD138; MUMI/ IRF4; CBP; MIB-1 (Ki-67 antigen); as well as anti-pancytokeratin. Polyclonal antibodies were used for the CD3 antigen, and for immunoglobulin light and heavy chains (IgL and $\mathrm{IgH}$, respectively). The antibodies were obtained from Dako (Glostrup, Denmark), Santa Cruz (CA, USA), Serotec (UK), Transduction and Novocastra (UK) (table 1), except for MUMl/IRF4, which was provided by Dr B Falini (Perugia, Italy). Bound antibodies were visualised using an indirect immunoperoxidase method ${ }^{19}$ for the antibodies to IgL and IgH, whereas the alkaline phosphatase anti-alkaline phosphatase (APAAP) method was used for the remainder. ${ }^{20}$ Double staining of some tumours was performed: the first antigen was detected by an avidin-biotin-peroxidase technique using diaminobenzidine/hydrogen peroxide as substrate, and the second antigen, by the APAAP procedure using naphthol AS-MX plus Fast Red TR (Sigma-Aldrich) as substrate. Incubation omitting the specific antibody was used as a control of the technique. The number of cells demonstrating clear nuclear positivity for MIBl was determined as described previously. ${ }^{21}$

Table 1 B cell and plasma cell associated antibodies used with corresponding clones and commercial source

\begin{tabular}{lll}
\hline Antibody & Clone & Company \\
\hline CD79a & JCB117 & Dako, Denmark \\
CD20 & L26 & Dako, Denmark \\
BSAP/PAX5 & 24 & Transduction Laboratories, Lexington, KY, USA \\
VS38c & Vs38c & Dako, Denmark \\
CD138 & B-B4 & Serotec, UK \\
CD38 & SPC32 & Novocastra, UK \\
CBP & C-1 & Santa Cruz Biotechnology, CA, USA \\
\hline
\end{tabular}

Definition of plasmacellular differentiation of EMZL

Ocular adnexal EMZL were defined as plasmacellular differentiated when $10 \%$ or more of the tumour cells displayed morphological features similar to plasma cells, such as eccentric nuclei, violet coloured or basophilic cytoplasm, the presence of Dutcher bodies, and/or Russell bodies, as defined in the literature (fig 1). ${ }^{22}$ Confirmation was achieved as proposed by other authors ${ }^{23}$ using immunohistochemical investigations for evidence of cytoplasmic (c) Ig and IgL restriction, negativity for BSAP/PAX5, and expression of at least one of the investigated plasma cell related antigens (VS38c, CD38, CD138, MUM1/IRF4, and CBP). Following a hypothesis that plasmacellular differentiated EMZL of the ocular adnexa which demonstrated immunoreactivity for a larger number (if not all) of the five investigated plasma cell related antigens possibly being better differentiated tumours than those which displayed positivity for only a few antigens, we repeated the statistical evaluations for all chosen end points by increasing the number of plasmacellular antigen expressed (for example, 2, 3, or 4) required in the inclusion criteria.

Normal plasma cells entrapped within the lymphoma were excluded from the evaluation. The distinction between such plasma cells and neoplastic cells with plasmacellular differentiation was based on features such as the maturity of cell morphology and the presence or absence of atypia (fig 1).

The staining of MUMI/IRF4 was localised predominantly to the nucleus, although weak cytoplasmic staining was also present in most cases with nuclear positivity. Strong staining in more than $20 \%$ of plasmacellular differentiated tumour cells was scored as positive, as defined by Tsuboi et al. ${ }^{24}$ Strong staining localised to the nucleus was considered positive for CBP; that localised to the plasma membrane was considered positive for $\mathrm{CD} 138$ and $\mathrm{CD} 38$; and that to the cytoplasm was considered positive for Vs38c.

\section{Medical history}

Detailed clinical information was gathered in all patients; those cases where significant data were not traceable, were excluded from the study. In order to obtain a follow up period of at least 2 years in patients still alive at the final examination, cases of ocular adnexal EMZL diagnosed after July 2000 were excluded. "Stage at presentation" was defined according to the modified Ann-Arbor classification scheme at the time of first diagnosis. Patients who had bilateral OAL without systemic manifestations were considered to have stage IE disease. "Primary disease" was defined as primary involvement of the ocular adnexa, corresponding to stage IE. "Secondary disease" was defined as a lymphomatous infiltration of the ocular adnexa by an identical lymphoma of another primary site.

\section{Statistical analysis}

Three clinically relevant end points were considered: (a) the development of local tumour recurrence; (b) the development of systemic disease; and (c) death related to lymphoma (time to event). For the three end point analysis, we also categorised the percentage of tumour cell expression for the proliferation marker MIBl as previously described. ${ }^{21}$ The association of categorical variables was assessed by cross tabulation, exact Pearson $\chi^{2}$ tests, and multiple logistic regression. Corresponding relative risks and odds ratios (multivariable) with 95\% confidence intervals were calculated. The equality of "time to event" distributions was investigated by Kaplan-Meier estimates of "survival curves," log rank tests, and (multiple) Cox regression. Corresponding hazard ratios (univariable and multivariable) with $95 \%$ confidence intervals were calculated. p Values (two tailed) lower than alpha $=5 \%$ were considered statistically significant 

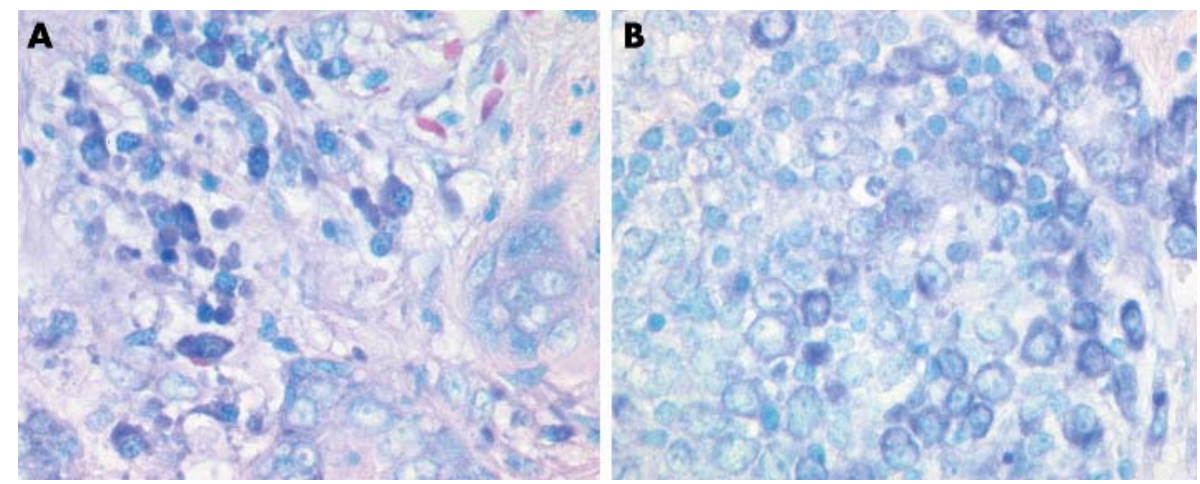

Figure 1 Illustration of normal and neoplastic plasma cells. (A) Normal plasma cells in lacrimal glands with their characteristic morphological appearance with eccentric nuclei with a "clock face" or "cartwheel" pattern distribution of chromatin, abundant cytoplasm, and distinct perinuclear holes. (B) Extranodal marginal zone B cells with a plasmacellular differentiation demonstrated violet coloured or basophilic cytoplasm, the presence of Dutcher bodies, and/or Russell bodies (see also fig $4 \mathrm{~B}$ ) as well as atypical nuclear features.
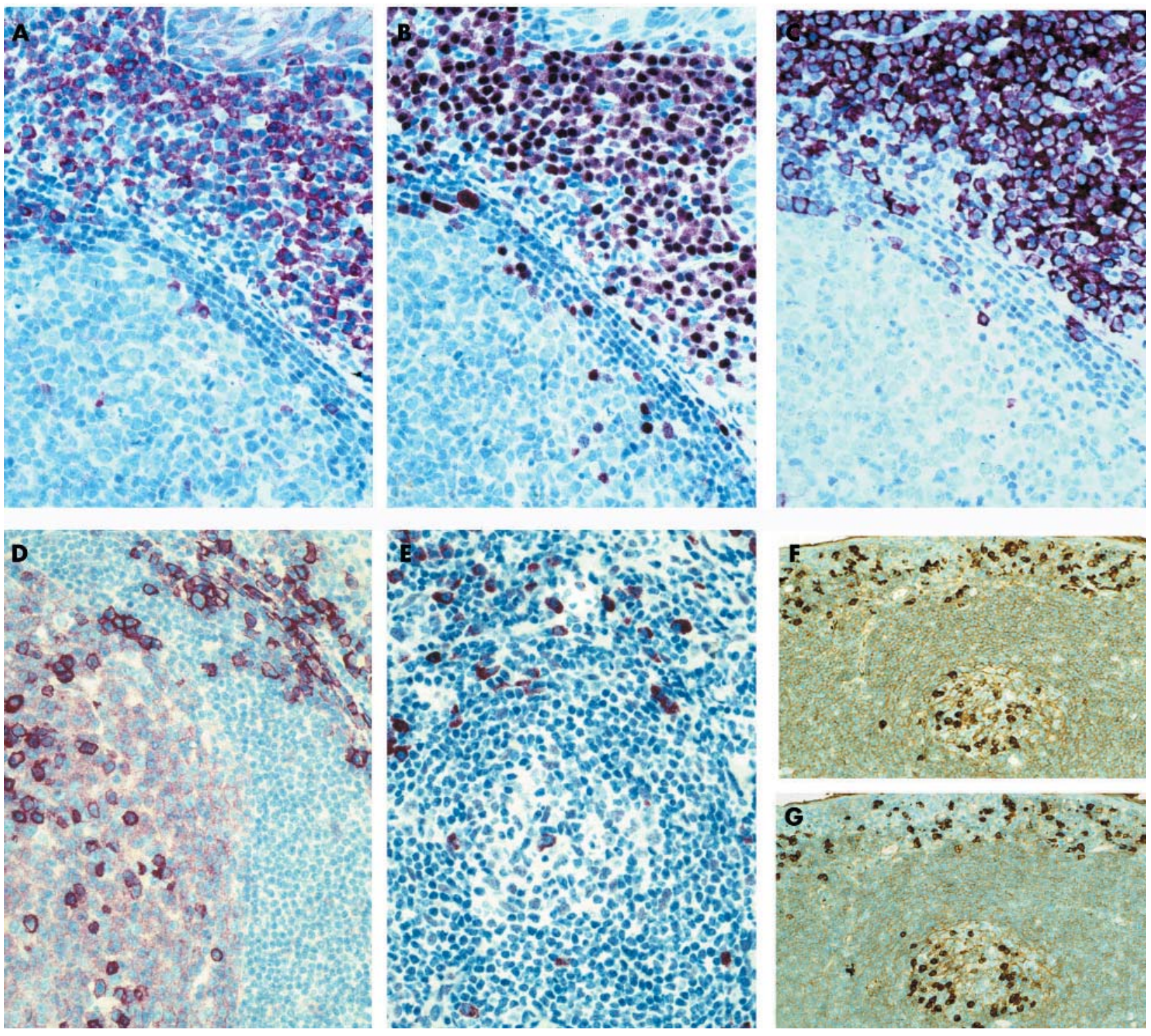

Figure 2 Expression of the five investigated plasma cell related antigens in reactive lymphoid tissue. Subepithelial reactive plasma cells in tonsils were positive for (A) Vs38c (cytoplasmic), (B) MUM1/IRF4 (nuclear), (C) CD138 (membranous), (D) CD38 (membranous), and (E) CBP (cytoplasmic), with polytypical expression for the light immunoglobulin chains kappa (F) and lambda (G). The tonsillar epithelium also demonstrates positivity for CD138 (C); while the germinal centre cells display mild to moderate expression of CD38 (D). Original magnification, $\times 1000$. 

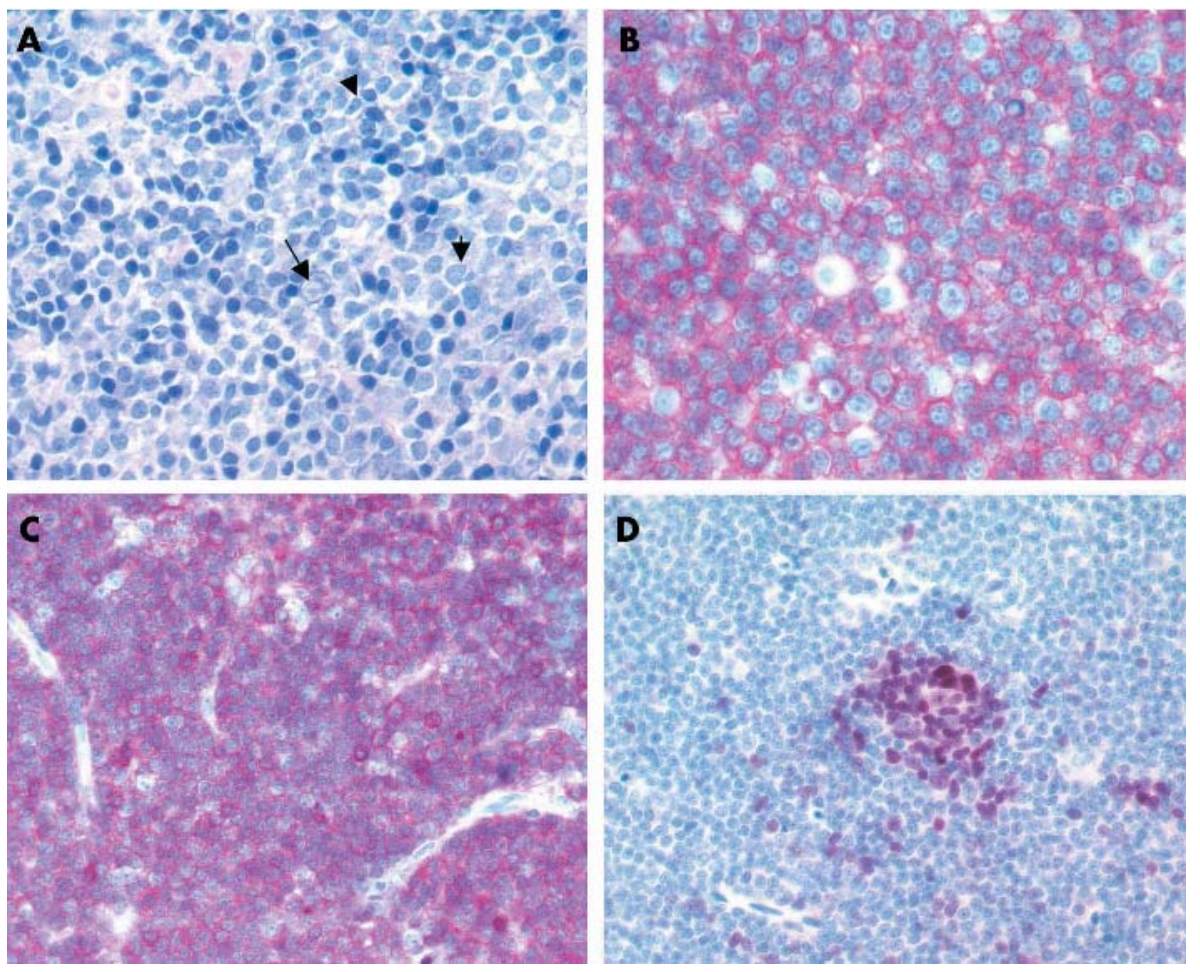

Figure 3 (A) EMZL without significant plasmacellular differentiation consisting of a heterogeneous population of centrocyte-like cells (arrowhead), monocytoid cells (medium arrow) as well as occasional blasts (long arrow) (Giemsa, original magnification $\times 400$ ). The tumour cells are positive for (B) CD20 and (C) demonstrate an aberrant expression of the T cell antigen CD43. (D) Occasional extrafollicular blasts are positive for $\mathrm{BCL}-6$. (APAAP, original magnification $\times 400$ ).

though not adjusted for multiple testing. All statistical analyses were performed using the software package SPSS for Windows, Release 11.0.1.

\section{RESULTS}

\section{Clinical features and anatomical distribution}

Most patients with ocular adnexal EMZL were female ( $\mathrm{F}=100 ; \mathrm{M}=36 ; \mathrm{F}: \mathrm{M} 2.7: 1$ ), with a median age of 64 years (range 19-91 years) at first diagnosis. The ocular adnexal EMZL were distributed as follows: orbit $(n=47+7$-that is, 47 stage IE and seven stage II, III, or IV) with lacrimal gland involvement in $8+2$ cases; conjunctiva $(n=41+7)$ and lid $(\mathrm{n}=2 \mathrm{l}+3)$. Synchronous bilateral EMZL were seen in $14+2$ patients. (In 43 cases, clinical information on this aspect was missing; however, subsequent treatment would indicate that these ocular adnexal EMZL must have been unilateral.) Most ocular adnexal EMZL (117 of 136 cases, 86\%) represented primary OAL (that is, stage I, IE lymphoma). Nineteen (14\%) of the EMZL patients had disseminated disease at the initial examination (that is, stage II, III, or IV), with the ocular adnexal tumours in 10 (53\%) of these cases representing secondary manifestations of systemic disease. In some patients with ocular adnexal EMZL, concurrent disease (representing stage IIE and above) was observed in other extranodal locations.

\section{Histology and immunohistology}

Normal or reactive hyperplastic tissues

The palatine tonsils and the interstitial tissue of the lacrimal glands contained an infiltrate of small bland mixed $\mathrm{T}$ and $\mathrm{B}$ lymphocytes with reactive lymphoid follicles. In the mantle zones, weak positivity for MUMI/IRF4 and CBP but not for Vs38c, CD38, or CD138 was observed (fig 2). Most germinal centre cells demonstrated weak to moderate positivity for CD38 (membranous; mainly centroblasts), but were negative for MUMl/IRF4, Vs38c, CD138, and CBP (fig 2). Several germinal centre cells in the light zone displayed strong nuclear and moderate cytoplasmic positivity for MUMl/IRF4 and Vs38c, respectively. Some marginal zone B cells showed weak nuclear immunoreactivity for MUMI/IRF4 and CBP, but were negative for Vs38c, CD38, and CD138.

Admixed plasma cells were seen in the subepithelial areas in the tonsils, in the interstitial tissue of the lacrimal glands, and occasionally in the reactive germinal centre. These cells demonstrated mature cytomorphology with basophilic cytoplasm, eccentric nuclei, clumped "clock faces" like chromatin and perinuclear halos. Virtually all plasma cells, which were negative for BSAP, demonstrated strong co-expression of CD79a, MUMl/IRF4-protein (nuclear strong, cytoplasmic weak), Vs38c (cytoplasmic), CD38 (membranous), CD138 (membranous), and CBP (nuclear strong, cytoplasmic weak), as well as polyclonal staining for IgH and IgL (fig 2). In some cases, occasional plasma cells failed to express CD138 and CBP. Varying immunoreactivity for Vs38c, CD138 (fig 2), and CBP but not for MUMl/IRF4 or CD38 was seen in the adjacent epithelium of the tonsils and lacrimal acini.

\section{Extranodal marginal zone B cell lymphoma}

Briefly, the EMZL consisted of small cells resembling centrocytes, monocytoid B cells, or small lymphocytes, with

Table 2 Immunophenotype of normal plasma cells as well as of non-plasmacytoid and plasmacytoid cells in EMZL

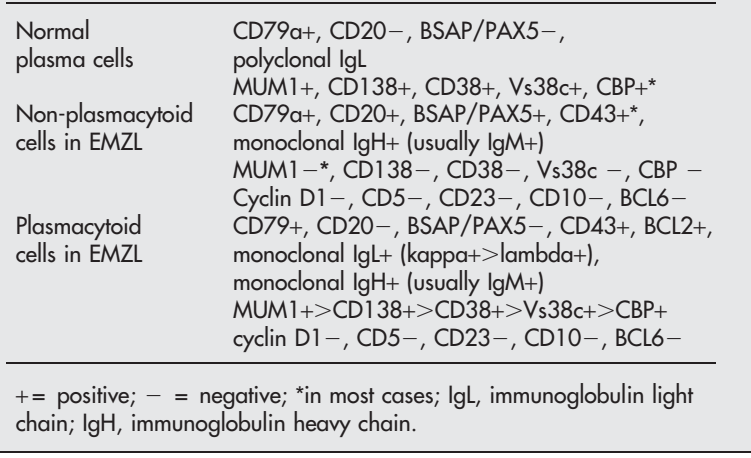


occasional blasts surrounding reactive B cell follicles (fig 3). Lymphoepithelial lesions were seen in some conjunctival specimens and in the orbital cases with lacrimal gland involvement. In most cases, the tumour cells expressed CD20, BSAP, CD79a, CD43, and BCL2 with absence of staining for CD10 and CD23 (fig 3) (table 2). Furthermore, scattered extrafollicular blasts stained for BCL6 or MUMI/IRF4 protein (fig 3). The MIBl growth fraction ranged from $2-50 \%$, median $10 \%$. In cases where an increased number of blasts were present in the marginal zone, an increased percentage of tumour cells $(>10 \%)$ positive for either BCL6 or MUMI/IRF4, together with an increased growth fraction, was observed.

Fifty seven of 136 (42\%) EMZL demonstrated plasmacellular differentiation, fulfilling the criteria as mentioned above (tables 2 and 3); 45 (33\%) of these "plasmacytoid" tumours represented stage I, IE EMZL. The tumour cells of the plasmacellular differentiated EMZL were positive for CD79a but negative for CD20 and BSAP (table 2). They demonstrated cIg and a monotypical expression for IgL or IgH, as well as a variable positivity for MUMI/IRF4, VS38c, CD38,
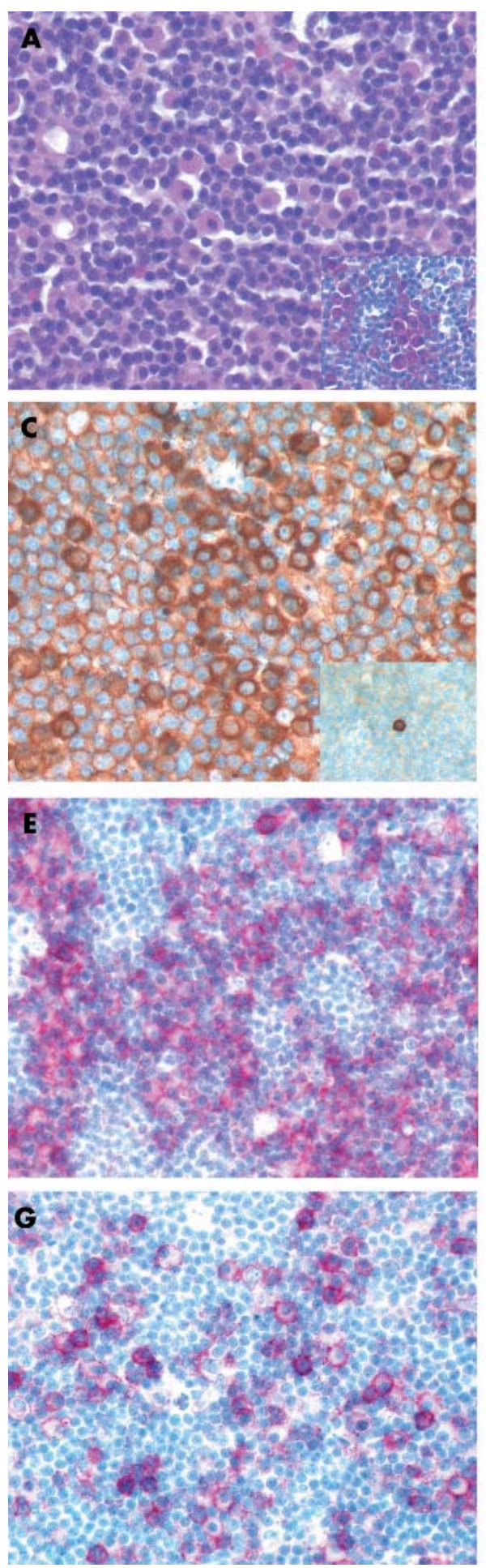
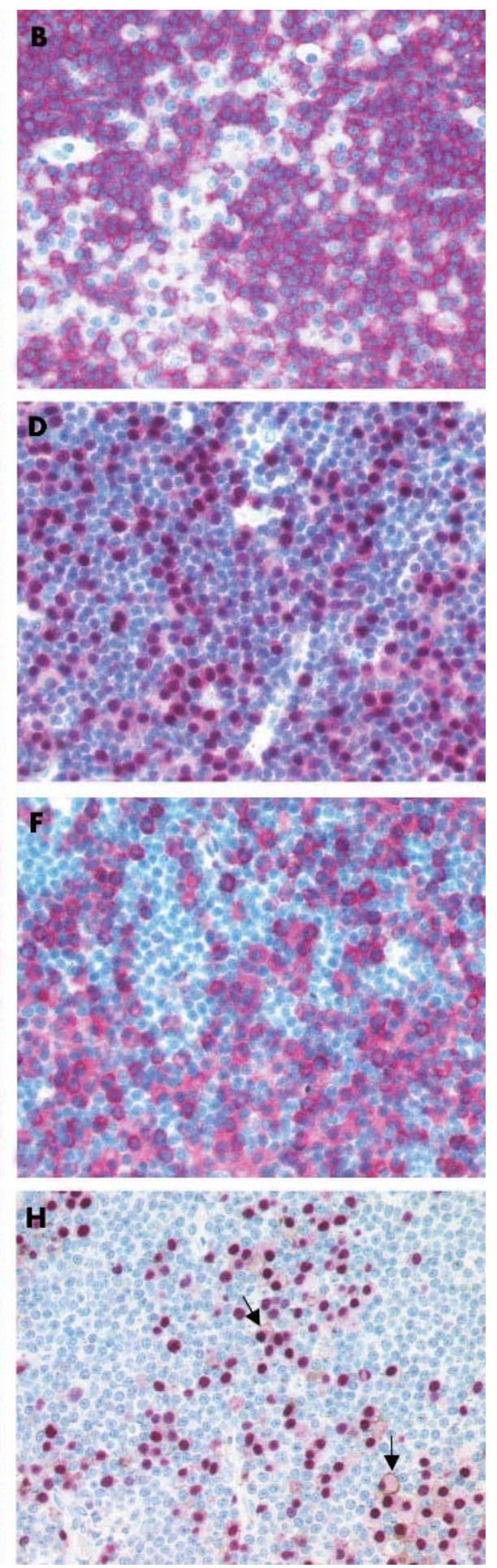

Figure 4 (A) EMZL with extensive plasmacellular differentiation (haematoxylin and eosin stain, original magnification $\times 400$ ). The

"plasmacytoid" cells are highlighted in the PAS stain (inset). (B) The plasmacellular differentiated tumour cells are negative for CD20 (arrow) (APAAP, original magnification $\times 400$ ). (C) A monotypical expression of the tumour cells for the immunoglobulin light chain kappa is seen. The contrasting stain for immunoglobulin light chain lambda is shown in the inset (PAP, original magnification $\times 400$ ). Immunoreactivity of the plasmacellular differentiated cells in the same EMZL for (D) MUM1/IRF4 (nuclear), (E) Vs38c (membranous), (F) CD138 (membranous), and (G) CD38 (APAAP, original magnification $\times 400)$. (H) Double staining for MUM1/IRF4 (PAP, brown nuclear) and CD38 (APAAP, red membranous), demonstrating only a small population of CD38/MUM1 positive cells (arrows), indicating the loss of CD38 expression by many of the MUM1 positive plasmacellular differentiated $B$ cells. (original magnification, $\times 400$ ). 
Table 3 Immunophenotype of the tumour cells in the plasmacellular differentiated ocular adnexal EMZL (BSAP negative, kappa, or lambda positive)

\begin{tabular}{|c|c|c|}
\hline \multirow[b]{2}{*}{ Immunophenotype* } & \multicolumn{2}{|l|}{ EMZL } \\
\hline & Stage I, IE & Stage II, III, IV \\
\hline $\mathrm{MUM1+/Vs38c+/CD138+/CD38+/CBP-}$ & 20 & 5 \\
\hline $\mathrm{MUM1}+/ \mathrm{Vs}_{\mathrm{S} 38 \mathrm{c}}-/ \mathrm{CD} 138+/ \mathrm{CD} 38+/ \mathrm{CBP}-$ & 11 & 2 \\
\hline $\mathrm{MUMl}+/ \mathrm{Vs}_{\mathrm{s}} 38 \mathrm{c}+/ \mathrm{CD} 138+/ \mathrm{CD} 38+/ \mathrm{CBP}+$ & 6 & \\
\hline $\mathrm{MUMl}+/ \mathrm{Vs}_{\mathrm{s}} 38 \mathrm{c}+/ \mathrm{CD} 138+/ \mathrm{CD} 38-/ \mathrm{CBP}-$ & 4 & \\
\hline $\mathrm{MUMl}+/ \mathrm{Vs}_{\mathrm{s}} 38 \mathrm{c}+/ \mathrm{CD} 138-/ \mathrm{CD} 38+/ \mathrm{CBP}+$ & 1 & 2 \\
\hline $\mathrm{MUMl}+/ \mathrm{Vs}_{\mathrm{s}} 38 \mathrm{c}+/ \mathrm{CD} 138-/ \mathrm{CD} 38+/ \mathrm{CBP}-$ & 1 & 1 \\
\hline $\mathrm{MUMl}+/ \mathrm{Vs}_{\mathrm{s}} 38 \mathrm{c}-/ \mathrm{CD} 138+/ \mathrm{CD} 38-/ \mathrm{CBP}-$ & 1 & 1 \\
\hline $\mathrm{MUMl}-/ \mathrm{Vs} 38 \mathrm{c}+/ \mathrm{CD} 138+/ \mathrm{CD} 38+/ \mathrm{CBP}-$ & 1 & \\
\hline $\mathrm{MUMl}+/ \mathrm{Vs}_{\mathrm{S}} 3 \mathrm{c}-/ \mathrm{CD} 138+/ \mathrm{CD} 38+/ \mathrm{CBP}+$ & & 1 \\
\hline Total & 45 & 12 \\
\hline
\end{tabular}

*The remaining plasma cells related antigen combinations were not represented in this sample of 136 lymphomas and are, therefore, not listed.

CD138, and CBP (fig 3) (tables 2 and 3). The most consistently expressed plasma cell related antigen of the plasmacytoid tumour cells was MUMl/IRF4, its immunoreactivity being seen in 56/57 (98\%) plasmacellular differentiated EMZL examined (fig 4). The other plasma cell related markers showed a variable expression with $\mathrm{CD} 138$ protein positivity in 52/57 (91\%) cases, CD38 in 51/57 (89\%), Vs38c in $41 / 57(72 \%)$, and CBP in $10 / 57$ (18\%) cases. Coexpression of all plasma cell related antigens by the "plasmacytoid" EMZL tumour cells was observed in only six of the $136(4 \%$, table 3$)$.

\section{Treatment}

The differing treatments of the 136 ocular adnexal EMZL were dependent on the stage of disease at time of diagnosis and included surgical excision, radiotherapy, chemotherapy, or various combinations of these. The most common form of therapy for stage I, IE EMZL patients was radiotherapy $(89 / 117=76 \%)$, with a dosage varying between $4 \mathrm{~Gy}$ and $50 \mathrm{~Gy}$. The follow up period of the patient collective was 2-239 months, median 49 months (4.1 years). In total, $32 / 136(24 \%)$ patients had died at last follow up, either as a result of lymphoma $(\mathrm{n}=18)$ or non-lymphoma related causes $(\mathrm{n}=14)$.

\section{Statistical analysis}

Either an ipsilateral or contralateral local recurrence occurred in $27(23 \%)$ of the 117 patients with ocular adnexal EMZL stage IE. The median time period between initial and recurrent tumour was 20 months. A systemic manifestation occurred in $38 / 117(32 \%)$ patients with stage IE ocular adnexal EMZL. The time period for the systemic disease manifestation to be clinically detected after diagnosis of ocular adnexal EMZL ranged from 2 to 125 months (median, 5 months).

Of the 136 EMZL patients, 18 (13\%) had succumbed to their disease at last follow up. Of these 18 patients, 10 (56\%) were diagnosed with localised disease at first diagnosis- that is, $8.5 \%$ of all patients in the group diagnosed with stage IE EMZL died as a result of lymphoma related causes.

The evaluation of the three end points and their relation to the degree of plasmacellular differentiation is summarised in table 4 and figure 5 . When applying the above mentioned definition of plasmacellular differentiation of tumour cells, a statistical significance could be demonstrated for the development of systemic disease on univariate analysis $(p=0.042)$. On multivariate analysis, however, this significance became weaker when adjusted for other important prognostic parameters previously described, ${ }^{12}{ }^{21}$ such as age at diagnosis (in years, $p=0.286$, odds ratio with $95 \%$ confidence interval: $1.02(0.98$ to 1.07$))$ and an increased growth fraction of the tumour cells (determined using MIBl, $>10 \%, \mathrm{p}<0.001$, OR with 95\% CI: 41.30 (12.50 to 136.40)) (table 4).

A statistical significance could not be demonstrated using univariate or multivariate analysis between plasmacellular differentiation of the tumour cells and either local tumour recurrence or lymphoma related death. For the latter, the parameters which reached statistical significance on multivariate analysis were (a) age at diagnosis (in years, $\mathrm{p}=0.058$, hazard ratio with 95\% confidence interval: 1.07 (1.00 to $1.15)$ ) and (b) an increased growth fraction ( $\mathrm{p}=0.006$, HR with 95\% CI: 6.01 (1.65 to 21.80)). As described above, alternative definitions of plasmacellular differentiation were investigated-that is, simultaneous negativity for BSAP, positivity for kappa or lambda and positivity of at least one, two, three, or four of the markers MUM1, CD138, VS38C, CD38, and CBP. Even when the tumour cells expressed more than one plasma cell related antigen, there was no significant alteration in the results for any of the end points (table 4).

\section{DISCUSSION}

Plasma cells are derived from B cells during immune responses $^{25} 26$ and can be essentially divided into short and long lived plasma cells. Short lived plasma cells, with a life span of a few days, are generated following the

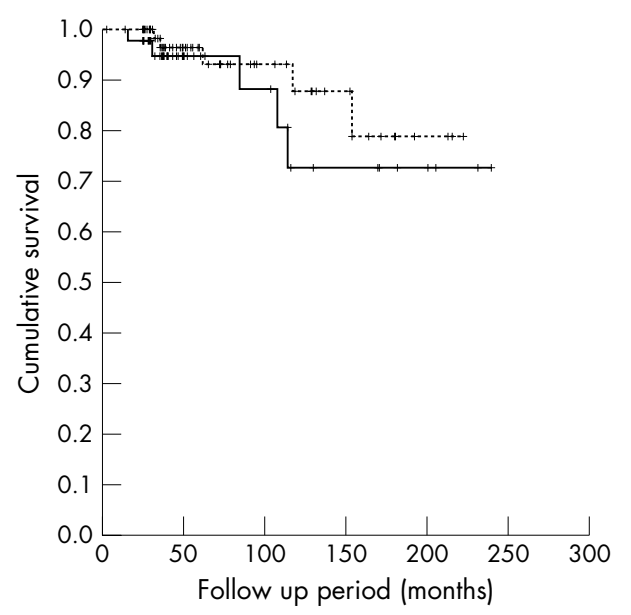

Figure 5 Kaplan-Meier estimate of survival curve for stage I, IE patients with (solid line) and without (broken line) plasmacellular differentiation defined as simultaneous negativity for BSAP, positivity for kappa or lambda and positivity of at least one of the markers MUM1, CDI38, VS38C, CD38, and CBP ( $p$ value from log rank test: 0.404 ; hazard ratio with $95 \%$ confidence interval: 1.69 (0.49 to 5.84 ); tick marks correspond to censored observations). 
transformation of IgM+/IgD+ "naive mature" B cells into extrafollicular B blasts after antigen contact. In contrast, long lived plasma cells, with a life span of possibly years, are derived either from germinal centre cells or from memory B cells, which have undergone the germinal centre reaction. Normally, long lived plasma cells are to be found only in peripheral lymphoid organs, the bone marrow, and at sites of immune responses, and are not detected in the peripheral blood. In their mature form, these cells have a typical morphological appearance, and are immunophenotypically characterised by positivity for CD79a, CD138, CD38, and Vs38c by negativity for CD20 and BSAP. ${ }^{27} 28$

Whereas CD79a is expressed during most stages of B cell differentiation, both $\mathrm{CD} 38$ and $\mathrm{CD} 138$ are present on pre-B cells, lost during differentiation, and are re-expressed at the plasma cell stage in normal cells. ${ }^{29}{ }^{30} \mathrm{Vs} 38 \mathrm{C}$ is also expressed at this terminal stage of B cell differentiation, when CD20 and BSAP antigens are lost. Recently, plasma cells have also been described as expressing MUMl/IRF4, ${ }^{31}$ known to be active in the control of plasma cell differentiation. The coactivator of the cyclic AMP responsive element binding protein (CREB) - namely the CREB binding protein (designated CBP), was included in the present study as we have observed a strong cytoplasmic expression of this transcriptional co-activator in plasma cells in our investigations of normal and neoplastic lymphatic tissues (unpublished results). At what point $\mathrm{CBP}$ is expressed during normal $\mathrm{B}$ cell differentiation is yet to be established.

In the current investigation, 136 ocular adnexal EMZL were analysed for their degree of plasmacellular differentiation on the basis of morphology, evidence of cIg, BSAP negativity, and the expression of five plasma cell related antigens. The results were subsequently correlated with three clinically relevant end points. Despite plasmacellular differentiation being described in up to $30 \%$ of EMZL, ${ }^{22}$ its clinical significance has not been subject to thorough investigation in any anatomical location to date. Furthermore, although some of the plasma cell related antigens investigated in the current study have been the subject of examination using both FACS and immunohistochemical analysis in haematopoietic malignancies, ${ }^{15} 2431-36$ there are only limited (or no) analyses of the prognostic value of these markers.

Similar to previous studies, ${ }^{24}{ }^{31}$ virtually all plasma cells in normal or hyperplastic lymphoid tissues demonstrated coexpression of Vs38c, CD138, and MUMl/IRF4. Many but not all mature peripheral plasma cells also displayed strong membranous and cytoplasmic reactivity for CD38 and CBP, respectively; 57/136 (42\%) EMZL examined demonstrated features of plasmacellular differentiation. In contrast with their non-plasmacellular differentiated counterparts, the "plasmacytoid" EMZL tumour cells were negative for the B cell marker BSAP, and demonstrated Ig light chain restriction as well as expression of at least one of MUMI/IRF4, VS38c,
CD38, CD138, or CBP. In contrast with normal plasma cells, the neoplastic tumour cells of only six plasmaceullular differentiated ocular adnexal EMZL demonstrated immunoreactivity for all five plasma cell related antigens (table 3).

MUMl/IRF4 protein was the most stable plasma cell related antigen in the "plasmacytoid" EMZL of the ocular adnexa, being observed in 56/57 (98\%) tumours (table 3 ). That MUMI/IRF4 expression is not exclusively observed in cells with plasmacellular differentiation has been previously reported by other authors. ${ }^{24} 3137$ However, only those cells with the corresponding cytomorphology, CIg/IgL, and BSAP negativity were considered in the interpretation of these stains. The remaining plasma cell related markers showed considerable variability with CD138 protein expression in $52 / 57$ (91\%) cases, CD38 in 51/57 (89\%), Vs38c in $41 / 57$ $(72 \%)$, and CBP in 10/57 (18\%) cases (table 3 ). Therefore, most plasmacellular differentiated tumour cells of ocular adenxal EMZL demonstrate an aberrant plasma cell related antigen profile when compared to normal plasma cells. This aberrant immune profile of "plasmacytoid" EMZL, which we described recently in uveal EMZL, ${ }^{38}$ may aid the establishment of malignancy in ocular adnexal lymphoproliferative lesions, particularly in those EMZL where the interpretation of light chain expression can be difficult.

Various parameters have been described to be of prognostic value in patients with $\mathrm{OAL}$, including anatomic location; ${ }^{39-42}$ stage at diagnosis; ${ }^{1271}$ lymphoma subtyping according to the REAL classification ${ }^{124673}$ and new WHO lymphoma classification; ${ }^{21}$ tumour cell growth fraction and increased blast percentages positive for BCL- $6^{1221}$; as well as serum lactate dehydrogenase. ${ }^{6}$ The results of the current data suggest, however, that the clinical significance of the presence and degree of plasmacellullar differentiation in EMZL of the ocular adnexa is not large. When defining plasmacellular differentiation of the tumour cells of the EMZL as described above, the relation between this tumour parameter and the development of systemic disease was statistically significant only on univariate analysis $(\mathrm{p}=0.042)$. This significance was lost, however, on multivariate analysis when other factors of previously described importance, ${ }^{12} 21$-namely age $>60$ years at diagnosis and an increased MIBl growth fraction of the tumour cells-were also considered.

Following a hypothesis that "plasmacytoid" EMZL of the ocular adnexa which demonstrated immunoreactivity for an increased number of the five investigated plasma cell related antigens (for example, $\geqslant 3$ ) possibly being better differentiated than those which displayed positivity for only a few of the antigens (for example, $<3$ ), we repeated the statistical evaluations for all chosen end points. However, there was no major alteration in the results for any of the end points investigated on multivariate analysis.

In summary, most plasmacellular differentiated tumour cells in ocular adnexal EMZL demonstrate an aberrant

Table 4 Stage I, IE lymphoma $(n=117)$ and association of alternative definitions of plasmacellular differentiation and development of local tumour recurrence, systemic disease, and death related to lymphoma

\begin{tabular}{|c|c|c|c|c|c|c|}
\hline \multirow{3}{*}{$\begin{array}{l}\text { Number of markers } \\
\text { positive for definition } \\
\text { of plasmacellular } \\
\text { differentiation }\end{array}$} & \multicolumn{2}{|c|}{ Development of local tumor recurrence } & \multicolumn{2}{|c|}{ Development of systemic disease } & \multicolumn{2}{|c|}{ Death related to lymphoma } \\
\hline & Univariate & Multivariate & Univariate & Multivariate & Univariate & Multivariate \\
\hline & $\operatorname{RR}(95 \% \mathrm{CI})$ & $\mathrm{OR}^{*}(95 \% \mathrm{Cl})$ & $\operatorname{RR}(95 \% \mathrm{CI})$ & $\mathrm{OR}^{*}(95 \% \mathrm{Cl})$ & $\mathrm{HR}(95 \% \mathrm{Cl})$ & $\mathrm{HR}^{*}(95 \% \mathrm{Cl})$ \\
\hline$\geqslant 1$ or $2 \dagger$ & $1.10(0.56$ to 2.15$)$ & $0.93(0.36$ to 2.40$)$ & $1.77^{* *}(1.06$ to 2.98$)$ & $1.38(0.44$ to 4.38$)$ & 1.69 (0.49 to 5.84$)$ & $1.10(0.29$ to 4.12$)$ \\
\hline$\geqslant 3$ & $0.98(0.49$ to 1.94$)$ & 0.77 (0.29 to 2.02$)$ & $1.65(0.99$ to 2.78$)$ & $1.01(0.31$ to 3.30$)$ & 1.20 (0.34 to 4.28$)$ & 0.70 (0.18 to 2.79$)$ \\
\hline$\geqslant 4$ & $1.17(0.55$ to 2.46$)$ & 1.08 (0.38 to 3.05$)$ & $1.73^{* *}(1.04$ to 2.90$)$ & 1.37 (0.38 to 4.94$)$ & 1.16 (0.24 to 5.54$)$ & 0.98 (0.19 to 5.07$)$ \\
\hline
\end{tabular}

$\mathrm{RR}$, relative risk (from cross tabulation); $\mathrm{OR}$, odds ratio (from logistic regression); HR, hazard ratio (from Cox regression);

${ }^{*}$ Adjusted for age at diagnosis and MIBI ( $\left.\leqslant,>10 \%\right)$.

** Statistically significant ( $p$ value $<5 \%$ ).

†These definitions did not yield different results on this dataset. 
immune profile for plasma cell related antigens when compared to normal plasma cells. On multivariate analysis, plasmacellular differentiation in ocular adnexal EMZL had no (or very little) value in the prediction of local recurrence, the development of systemic disease, or for lymphoma related death. Strong predictors of (a) systemic tumour dissemination and (b) lymphoma related death included advanced age at diagnosis and an increased MIB-1 growth fraction. None of the investigated parameters in the current study seem to be predictive of local tumour recurrence.

\section{Authors' affiliations}

S E Coupland, I Anagnostopoulos, H Stein, Department of Pathology, Charite-Medical Faculty Berlin, Campus Benjamin Franklin, Berlin,

Germany

M Hellmich, Department of Medical Statistics, Informatics and Epidemiology, University of Cologne, Germany

C Auw-Haedrich, Department of Ophthalmology, University Hospital Freiburg, Germany

W R Lee, Department of Pathology, Western Infirmary, Glasgow, UK

\section{REFERENCES}

1 Auw-Haedrich C, Coupland SE, Kapp A, et al. Long term outcome of ocular adnexal lymphoma subtyped according to the REAL classification. Br J Ophthalmol 2001;85:63-9.

2 Coupland SE, Krause L, Delecluse HJ, et al. Lymphoproliferative lesions of the ocular adnexa. Analysis of 112 cases. Ophthalmology 1998;105:1430-41.

3 Hardman-Lea S, Kerr-Muir M, Wotherspoon AC, et al. Mucosal-associated lymphoid tissue lymphoma of the conjunctiva. Arch Ophthalmol 1994; 112:1207-12

4 Jenkins C, Rose GE, Bunce C, et al. Histological features of ocular adnexal lymphoma (REAL classification) and their association with patient morbidity and survival. Br J Ophthalmol 2000;84:907-13.

5 Mannami T, Yoshino T, Oshima K, et al. Clinical, histopathological, and immunogenetic analysis of ocular adnexal lymphoproliferative disorders: characterization of malt lymphoma and reactive lymphoid hyperplasia. Mod Pathol 2001;14:641-9.

6 Nakata M, Matsuno Y, Katsumata N, et al. Histology according to the Revised European-American Lymphoma Classification significantly predicts the prognosis of ocular adnexal lymphoma. Leuk Lymphoma 1999;32:533-43.

7 White WL, Ferry JA, Harris NL, et al. Ocular adnexal lymphoma. A clinicopathologic study with identification of lymphomas of mucosa-associated lymphoid tissue type. Ophthalmology 1995;102:1994-2006.

8 Jaffe ES, Harris NL, Stein H, et al. World Health Organization classification of tumours. tumours of haematopoietic and lymphoid tissues. pathology and genetics. Lyons: IARC Press, 2001.

9 Isaacson PG. Mucosa-associated lymphoid tissue lymphoma. Sem Hematol 1999;36:139-47.

10 Salhany KE, Pietra GG. Extranodal lymphoid disorders. Am J Clin Pathol 1993;99:472-85.

11 Baldini L, Blini M, Guffanti A, et al. Treatment and prognosis in a series of primary extranodal lymphomas of the ocular adnexa. Ann Oncol 1998;9:779-81.

12 Coupland SE, Hummel M, Stein H. Ocular adnexal lymphomas: five case presentations and a review of the literature. Surv Ophthalmol 2002;47:470-90.

13 Harris NL, Isaacson PG. What are the criteria for distinguishing MALT from non-MALT lymphoma at extranodal sites? Am J Clin Pathol 1999;111:S126-32.

14 Isaacson PG, Norton AJ. Extranodal lymphomas. London: Churchill Livingstone, 1994.

15 Chang CC, Lorek J, Sabath DE, et al. Expression of MUM1/IRF4 correlates with clinical outcome in patients with B-cell chronic lymphocytic leukemia. Blood 2002; 100:4671-5.

16 Papamichael D, Norton AJ, Foran JM, et al. Immunocytoma: a retrospective analysis from St. Bartholomew's Hospital-1972 to 1996. J Clin Oncol $1999 ; 17: 2847-53$.
17 Richards MA, Hall PA, Gregory WM, et al. Lymphoplasmacytoid and small cell centrocytic non-Hodgkin's lymphoma-a retrospective analysis from $\mathrm{St}$ Bartholomew's Hospital 1972-1986. Hematol Oncol 1989;7:19-35.

18 Norton AJ, Jordan S, Yeomans P. Brief, high-temperature heat denaturation (pressure cooking): a simple and effective method of antigen retrieval for routinely processed tissues. J Pathol 1994;173:371-9.

19 Hsu SM, Raine L, Fanger H. Use of avidin-biotin-peroxidase complex $(A B C)$ in immunoperoxidase techniques: a comparison between $A B C$ and unlabeled antibody (PAP) procedures. J Histochem Cytochem 1981;29:577-80.

20 Cordell JL, Falini B, Erber WN, et al. Immunoenzymatic labeling of monoclonal antibodies using immune complexes of alkaline phosphatase and monoclonal anti-alkaline phosphatase (APAAP complexes). J Histochem Cytochem 1984:32:219-29.

21 Coupland SE, Hellmich M, Auw-Haedrich C, et al. Prognostic value of cellcycle markers in ocular adnexal lymphoma: an assessment of 230 cases. Graefes Arch Clin Exp Ophthalmol 2004;242:130-45.

22 Harris NL, Jaffe ES, Stein $\mathrm{H}$, et al. A revised European-American classification of lymphoid neoplasms: a proposal from the International Lymphoma Study Group. Blood 1994;84:1361-92.

23 Sebestyen A, Kovalszky I, Mihalik R, et al. Expression of syndecan-1 in human B cell chronic lymphocytic leukaemia. Eur J Cancer 1997;33:2273-7.

24 Tsuboi K, lida S, Inagaki $\mathrm{H}$, et al. MUM1/IRF4 expression as a frequent event in mature lymphoid malignancies. Leukemia 2000;14:449-56.

25 MacLennan IC. Germinal centers. Annu Rev Immunol 1994;12:117-39.

26 MacLennan IC, Casamayor-Palleja M, Toellner KM, et al. Memory B-cell clones and the diversity of their members. Sem Immunol 1997;9:229-34.

27 Barberis A, Widenhorn K, Vitelli L, et al. A novel B-cell lineage-specific transcription factor present at early but not late stages of differentiation. Genes Dev 1990;4:849-59.

28 Jego G, Robillard N, Puthier D, et al. Reactive plasmacytoses are expansions of plasmablasts retaining the capacity to differentiate into plasma cells. Blood 1999;94:701-12.

29 Sanderson RD, Lalor P, Bernfield M. B lymphocytes express and lose syndecan at specific stages of differentiation. Cell Regul 1989;1:27-35.

30 Mehta K, Shahid U, Malavasi F. Human CD38, a cell-surface protein with multiple functions. Faseb J 1996;10:1408-17.

31 Falini B, Fizzotti M, Pucciarini A, et al. A monoclonal antibody (MUM1p) detects expression of the MUM1/IRF4 protein in a subset of germinal center $B$ cells, plasma cells, and activated T cells. Blood 2000;95:2084-92.

32 Almeida J, Orfao A, Mateo G, et al. Immunophenotypic and DNA content characteristics of plasma cells in multiple myeloma and monoclonal gammopathy of undetermined significance. Pathol Biol (Paris) 1999;47:119-27.

33 Dogan A, Bagdi E, Munson $\mathrm{P}$, et al. $\mathrm{CD} 10$ and $\mathrm{BCL}-6$ expression in paraffin sections of normal lymphoid tissue and B-cell lymphomas. Am J Surg Pathol 2000;24:846-52.

34 Fernandez JE, Deaglio S, Donati D, et al. Analysis of the distribution of human CD38 and of its ligand CD31 in normal tissues. J Biol Regul Homeost Agents 1998;12:81-91.

35 Keyhani A, Huh YO, Jendiroba D, et al. Increased CD38 expression is associated with favorable prognosis in adult acute leukemia. Leuk Res 2000;24:153-9.

36 Rawstron A, Barrans S, Blythe D, et al. Distribution of myeloma plasma cells in peripheral blood and bone marrow correlates with CD56 expression. Br J Haematol 1999; 104:138-43.

37 Natkunam Y, Warnke RA, Montgomery K, et al. Analysis of MUM1/IRF4 protein expression using tissue microarrays and immunohistochemistry. Modern Pathol 2001;14:686-94.

38 Coupland SE, Foss HD, Hidayat AA, et al. Extranodal marginal zone B cell lymphomas of the uvea: an analysis of 13 cases. J Pathol 2002;197:333-40.

39 Jakobiec FA, Knowles DM. An overview of ocular adnexal lymphoid tumors. Trans Am Ophthalmol Soc 1989;87:420-42, discussion 442-4.

40 Johnson TE, Tse DT, Byrne GE Jr, et al. Ocular-adnexal lymphoid tumors: a clinicopathologic and molecular genetic study of 77 patients. Ophthal Plast Reconstr Surg 1999;15:171-9.

41 Knowles DM, Jakobiec FA, McNally L, et al. Lymphoid hyperplasia and malignant lymphoma occurring in the ocular adnexa (orbit, conjunctiva, and eyelids): a prospective multiparametric analysis of 108 cases during 1977 to 1987. Hum Pathol 1990;21:959-73.

42 Sigelman J, Jakobiec FA. Lymphoid lesions of the conjunctiva: relation of histopathology to clinical outcome. Ophthalmology 1978;85:818-43.

43 Knowles DM, ed. Neoplastic hematopathology. Chapter 35. Philadelphia: Lippincott Williams and Wilkins, 2000. 